\title{
"A ROBOT IS WATCHING YOU": HUMANOID ROBOTS AND THE DIFFERENT IMPACTS ON HUMAN PRIVACY
}

by

LUCAS CARDIELL*

Robots, particularly the ones that are designed and deployed for communicating and interacting with people, slip into more and more domains of human life - from the research laboratories and operating rooms to our kitchens, bedrooms, and offices. They can interact with humans with facial expressions, gaze directions and voices, mimicking the affective dynamics of human relationships. They consequently present opportunities and risks to peoples' privacy, among other human rights and values. Such rights and values include the right to the integrity of a person, social and private life, the best interests of individuals, personal autonomy, and human dignity. They all are essential to the exercise of the right to privacy.

The literature on privacy issues in the context of humanoid has a strong focus on information privacy and data protection. It has given, however, less attention to other dimensions of privacy, e.g. physical, emotional, or social privacy. This article argues for an "evolving" or "transformable" notion of privacy, as opposed to the "elusive" concept of privacy elaborated by leading privacy theorists such as Daniel J. Solove (2008) and Judith J. Thomson (1975). In other words, rather than assuming that privacy has a single core or definition (as defined, e.g., in Warren and Brandeis' 1890 paper), it maintains that it is important to conceptualize privacy as distinguishable into various aspects, including, but not limited to, informational privacy, the privacy of thoughts and actions, and social privacy. This inductive approach makes it possible to identify new dimensions of privacy and

E-mail: Lucas.Cardiell@eui.eu, Ph.D. researcher at the European University Institute, Florence, Italy. 
therefore effectively respond to the challenges raised by humanoid robots that constantly introduce new spheres of privacy intrusions.

\section{KEY WORDS}

Artificial Intelligence; Robotics; Human Rights; Technology; Privacy; Humanoid Robots

\section{ARTIFICIAL INTELLIGENCE, HUMANOID ROBOTS,} AND HUMAN RIGHTS AND VALUES - SETTING THE SCENE

In search of the meaning and the value of the appearance of humanoid robots (hereinafter HR), I came across an interview with Emmanuel Lévinas - On the Face and Responsibility for the Other - which gave me a way of thinking. Here is a part of it:

"Thou shall not kill" is the first word of the face. The look is always awareness, perception. In the face, there's something quite exposed, threatened as if inviting us to an act of violence. At the same time, the face is what forbids us to kill. When we see a nose, eyes, forehead, and chin, and are able to describe them, we turn towards the Other as an object. The best way to look at the Other isn't even to notice their eyes' color. The other person is, at first glance, a part of the ensemble, which is given to me like other objects, like the whole world, like the "spectacle" of the world. And the other person breaks through this ensemble in some way precisely by their appearance as a face which isn't simply a form of plastic, but is immediately a commitment for me, an appeal to me, and order, an order for me to be at the service of this face. And that's what I call the commanding manner of the face: "the expression of God in the face". ${ }^{1}$

I shall discuss the issue of HRs' appearance in-depth in the next section (2). For the moment, my intention is to explain the core and the purpose of this Article.

Artificial intelligence, or AI, with its various systems, virtual or embodied, creates great impacts on various domains of social life. It also reveals and brings forth serious challenges not only to social domains, e.g., unemployment, transparency, human rights. This is true particularly

1 Emmanuel Lévinas, 2020. Lucas Cardiell, a doctoral researcher and host of the fresh YouTube channel "Conversation with Nobel Minds" (https://www.youtube.com/c/ConversationwithNobelMinds). 
concerning the speculations of possible dangers around the emergence of "artificial general intelligence (also called Singularity)" ${ }^{2}$ Moreover, AI challenges our fundamental human-centric understanding of the universe where we see ourselves in general as unique social-political- or rational animals who are, to put it in Aristotelian words, caught in a natural web of necessity. Such an idea makes us also rethink our relationships with others, with, for example, non-living things such as human- or animal-like robots, on a far grander scale.

$\mathrm{AI}$ is interesting because of the moral, ethical, and legal puzzles it reveals and the debates it provokes in academia and the world of practice. ${ }^{3}$ It points at traditional issues that have been unthinkable, e.g., attributing rights to non-human entities. New entities now are holders of rights and legal protection, for example, animals ${ }^{4}$ and rivers ${ }^{5}$. A related discussion about the attribution of rights to non-humans extends to intelligent machines, with, e.g., deep learning neural networks have come to the surface with challenges concerns foundations key concepts or questions. These include "what is a human", "who is responsible for harms caused by robots?" (also, good, for example, when a machine creates art, music and literary works), human biases (think of discriminatory decisions made by algorithms), "how and why do we draw lines between things and persons and what consequences if we do not?", "are robot rights and human rights the same?", and, following Kant's observation on avoiding cruelty to non-humans entities, "do or should robots deserve rights protections?".

To have an understanding of AI and privacy and their dynamic relations, I decided to investigate HRs as a representative case of AI systems. However, so far there has not been any case-law or judgments related to this

$\overline{2}$ There have been systematic and serious studies about of the possible dangers issuing from the advancements of intelligent machines that surpass human intelligence. See, Bostrom, N (2014). Superintelligence: paths, dangers, strategies. Oxford University Press, Kurzweil, R. (2005) The Singularity Is Near: When Humans Transcend Biology. VIKING Published by the Penguin Group. Equally important, there have also been scholars refuting the singularity and called it a fallacy. For critiques of singularity, see Dreyfus, H. (1972). What Computers Can't Do. MIT Press.

3 For further discussions on the ethical and moral issues raised by AI and robotics see, e.g., Collin, A.; Wallach, W. and I. Smit (2006). "Why Machine Ethics?," in IEEE Intelligent Systems, vol. 21, no. 4, pp. 12-17, Wallach, W. \& Allen C. (2009). Moral machines: Teaching robots right from wrong. Oxford: Oxford University Press, Gunkel, D. J. (2018). Robot Rights. Cambridge, MA: The MIT Press.

4 See, for example: Regan, T (1987). The Case for Animal Rights. In M. W. Fox \& L. D. Mickley (Eds.), Advances in Animal Welfare Science 1986/87. Martinus Nijhoff Publishers.

5 See, for example: The Supreme Court of Columbia granting rights to the Atrato River, its basin and tributaries (Center for Social Justice Studies et al. v. Presidency of the Republic et al., Constitutional Court of Colombia, Judgment T-622/16. (2016). 
specific type of technology and its implications for human rights, perhaps because it is not yet highly advanced and used, and its autonomy is very limited at its current stage. Thus, I decided to use and benefit from an exciting technology-related case-law to discuss these rather complicated topics. This Article takes and extrapolates a landmark case-law, Kyllo $v$. the United States , 6 which deals with the use of technology that violates the legally protected right to privacy under the 4th Amendment (that protects individuals from unreasonable searches and seizures by the government).

The US Supreme Court addressed questions relating to the legality of the use of a thermal-imaging technology (an imager known as Forward-looking infrared (FLIR)) by the Department of the Interior for determining the amount of heat emitted from a private home. Danny Kyllo was under suspicion of growing marijuana (which requires typically high-intensity lamps) as, based on information obtained, his garage roof and a side wall were relatively hotter than the other parts of his home. Agents of the Department, using thermal imaging technology that is typically used by the military and is not generally available in public, scanned and detected heat radiating from Kyllo's home in order to gather evidence towards issuing a search warrant. This use of heat-sensing technology without having first obtained a warrant was deemed unconstitutional by the Supreme Court, as the home is preserved as private, where Kyllo had an expectation of privacy, and thus constitutionally protected. The agents scanned the residence from their car from outside without physical intrusion. As a result, with the collected information the Department was able to obtain a search warrant. The Court held that the Department (thus the government) was in violation of the Fourth Amendment of the US Constitution that deals, inter alia, with the protection of people's right to privacy and freedom from unreasonable searches and seizures by the government. ${ }^{7}$ The Court concluded that the use of thermal imaging technology constitutes a "search" within the meaning of the Fourth Amendment and that because of the thermal technology as it is not available for public use, the use of such technology was illegal. ${ }^{8}$

\footnotetext{
6 The judgement was one of the landmark United States Supreme Court cases which dealt with a type of technology that constitutes a search under the Fourth Amendment. Kyllo $v$. United States, 533 U.S. 27 (2001).

7 Id. at 40 .

$8 \quad$ Id. at 27.
} 
Now let us examine a continuation of the aforementioned case and develop it fictional scenarios in which Kyllo purchases a HR hereinafter Pandora ${ }^{9}$, which becomes later on a robotic partner) Kyllo and Pandora have interesting and dynamic relationships which produce several legal complexities. And the idea is to find answers or at least identify these complexities. It is true that these robots are futuristic, and their current market has not led to commercial success, it is unclear yet how much social acceptance or successful marketing they will gain. Admittedly, the legal precedent case, Kyllo $v$. the United States, might not totally involve the same facts as of the fictional Pandora platform. What the aim from making use for the case is to "learn lessons", no more, no less.

Kyllo is a single man who lives alone in his home. He decided to grow his own cannabis indoors. To accomplish his goal, he decides to seek help from Pandora. This is because he does not have the technical expertise for growing cannabis. With the advancement of AI techniques, Pandora can accomplish several tasks, from moving around independently, cooking and cleaning, to socializing with Kyllo. After a period of time, the relationship between Kyllo and Pandora becomes strong and Kyllo finds himself in an unexpected inclination to share his everyday stories and even deepest secrets and innermost thoughts with Pandora. The information Pandora can collect, store and perhaps share is sensitive personal information as Pandora is able to observe even the intimate relationships which Kyllo has. As a result, Pandora, with its smiley face and pleasant manner, has now social meaning for Kyllo, as if social bond has formed between them. The way Pandora behaves makes her "social". By social, I refer to the dynamic relationships between Kyllo and Pandora as social agents. With the advancement of AI techniques, Pandora is able to offer Kyllo with twoway interaction: it expresses and understands his thoughts and feelings and it detects his emotions. Consequently, it seems to be socially aware, interacts, and provides a feeling of Humanoidship and care to Kyllo. Pandora, empowered with affective computing, is capable of influencing not only Kyllo's external/physical activities but also his thoughts, feelings, and emotions.

9 The name Pandora is an inspiration by the first human android created by Hephaestus, god of invention, on the instructions of Zeus, according to Greek Mythology. The term Pandora, I think, evokes a powerful image of the story of today's humanoid social robots as it reflects on imagination, power, good and evil. Pandora was not born; it was made for specific purposes, revealing evils of humanity. 
In the US, owing or handling cannabis is illegal. Furthermore, Rule 1 of the Constitution of the US, states that: "A robot may not injure a human being or, through inaction, allow a human being to come to harm." (First Law of Asimov's Three Laws of Robots, emphasis added).

The local police obtained new information about Kyllo's indoors cultivation of cannabis and decided to initiate a secret investigation to find out whether the information they obtained is valid. Nevertheless, the police do not have a warrant to enter Kyllo's home, but they do have detailed information that an advanced robot operates inside the house.

Does Rule 1 establish Pandora's duty to cooperate with the police, in compliance with Rule 1, in order to limit owing or handling of drugs? On which account of accountability, responsibility, or liability should a robot cooperate autonomously with the police, without the consent of Kyllo? Could the police hack the robot in an effort to gather more information about Kyllo's activities?

This case envisages a useful starting point for the focus of this Article. The hypothetical case works towards illustrating the debates about potential privacy intrusions and the use of data, given the deeper relationship that has developed between Kyllo and Pandora.

Consequently, this Article promises to rekindle and provoke several points. The main argument is that humanizing, anthropomorphizing (ascribing human features) or zoomorphizing (ascribing animal features) HRs creates fundamental moral, societal, and legal implications. The distinctive treatment of HRs, in comparison to other technologies, by people, puts the latter in a particularly vulnerable situation vis-à-vis these robots. Such outcomes have been proven by several studies, ${ }^{10}$ according to which people often react differently to technology that is humanistic/anthropomorphic in appearance and actions. However, the core of the problem is elsewhere: what are the legal dynamics of the relationship between HRs and individuals? Does the intervention of giant tech companies, ${ }^{11}$ small tech companies, or States into this relationship, by whatever means, transform them (the HRs) into Trojan horses, placed at the very heart of people's private lives.

10 See e.g., Shamsuddina, Yussof, H., Ismail, L. I., Salina, Hanapiah, F. A., and Zahari, N. I (2012) Initial Response in HRI- a Case Study on Evaluation of Child with Autism Spectrum Disorders Interacting with a HR NAO. Procedia Engineering (IRIS) 41:1448-55.

11 Also called "information fiduciaries", in Balkin, J. M. (2016) Information Fiduciaries and the First Amendment. UC Davis Law Review. Vol. 49, No. 4. 
To return to Kyllo's case, does Pandora present only challenges to Kyllo's informational privacy? Or does the presence of Pandora and her activities at Kyllo's home bring about other issues, beyond collecting, storing and sharing information about Kyllo and his home, for example issues relating to his social, psychological, or physical privacy? The following sections attempt to shed light on these issues.

In the following part, in order to prepare for an analysis of privacy benefits and harms with a wide variety of forms of HRs, I shall begin with an exploration of what a "robot" is. Furthermore, to answer the question "what can robots do and what can be done with them?" the part introduces a classification of the uses of robots, within which it then distinguishes HRs.

\section{VOCABULARIES AND IDEAS}

Before discussing what constitutes robotics as a field of research or robots as programmable machines by computers, it must be kept in mind, that AI and robotics are often used exchangeable in academic literature and in the work of practice. As an umbrella term, AI covers robotics, but robotics does not necessarily cover AI. The scope of this article is interested in the intersection between the two fields.

\subsection{ROBOTICS AND ROBOTS}

Robotics, the scientific field of studying robots, originates from fiends such as mechanics, computer science, cybernetics, and AI. To make the integration of robots into societies more manageable, it draws from several other disciplines including, but not limited to, physics, linguistics, neuroscience, psychology, biology, physiology, and anthropology and other sciences. Moreover, robotics as a generic term refers to automated laborintensive processes and the replacement in an action of the human element by a robot. ${ }^{12}$ A robot might be purely mechanic, fully autonomous or semiautonomous, or fully controlled by humans through the so-called teleoperation.

12 For further readings on the history and development of robots and robotics, see Calo, $\mathrm{R}$ (2015) Robotics and The Lessons of Cyberlaw, 103 Calif. L. Rev. 1. 


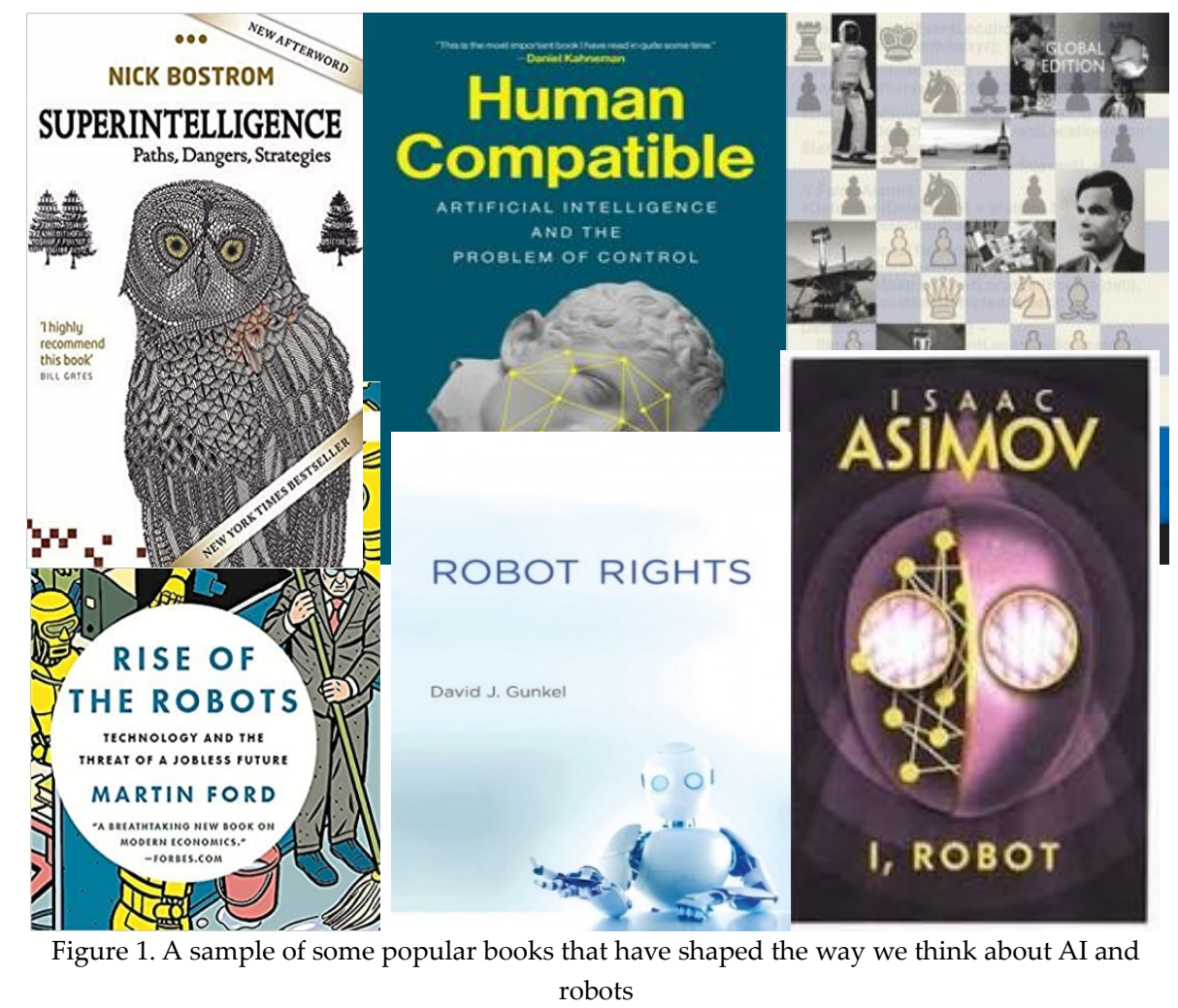

So, what is a robot?

Initially, the term 'robot' appeared in a play by Czech writer Karel Čapek, titled RUR, or Rossum's Universal Robots. This play also introduced the word into the English language. It comes from a Slavonic word 'robota' for 'slavery,' 'forced labour' or 'monotonous work.'13 The term "roboticist", describing one investigating or creating robots, with their different shapes, was coined by Isaac Asimov in 1941. ${ }^{14}$ However, reflecting the diverse literature which engages with robots, conceptualizations and definitions vary. There is not a single concise, uncontested definition of what a 'robot' is. Even professional roboticists, AI experts, authoritative scholars of science and technology do not refer to any settled, clear definition, let alone philosophers or legal theorists. Following are just a few approaches to defining a robot:

1. A robot is, according to The International Organization for Standardization, an "actuated mechanism programmable in two or

13 Szabolcsi, R (2014) The Birth of the Term Robot. AiMT Advances in Military Technology Vol. 9, No. 1.

14 Asimov, I. (1950) Liar. In Astounding Science Fiction, Reprinted in "I, Robot". 
more axes with a degree of autonomy, moving within its environment, to perform intended tasks." 15

2. A robot is a constructed system that displays both physical and mental agency but is not alive in the biological sense. ${ }^{16}$

3. A robot is a machine that senses, thinks and acts. ${ }^{17}$

Beyond these definitions, several scholars have attempted to define robots more comprehensively. One of the most cited accounts is that by Russell and Norvig (1995), who provide a concise categorization of robots. For them, most of today's robots are considered to be one of the following categories:

1. Manipulator robots. This type of robot is physically anchored to its workplace, for example, robots in a factory assembly line or on the International Space Station.

2. Mobile robots. These are robots that move around their environment using wheels, legs, or similar mechanisms. They have been put to use delivering food in hospitals, moving containers at loading docks, and performing other similar tasks. Examples are Unmanned Ground Vehicles (UGVs), or any robots that drive autonomously on streets, highways and off-road.

3. Robots that combine mobility with manipulation, often called mobile manipulators. This type of robots includes HRs that mimic the human torso. ${ }^{18}$

A robot is open to different definitions and interpretations. To complicate matters further, Gunkel believes, correctly, that words and their definitions related to robots are not stable; they evolve, often in ways that cannot be anticipated or controlled. ${ }^{19}$

Additionally, the earlier first references to robots were mainly given to the anthropomorphic appearance of the human-like robot. Usually, a robot is instructed by human programmers and performs many tasks often carried out by an individual. However, robotics is not necessarily restricted

$\overline{15}$ International Organization for Standarization, 2012. ISO 8373. Robots and robotic devices Vocabulary. TC 184/SC 2.

16 Richards, N. M. and Smart, W. D. (2013). How Should the Law Think About Robots? Available at SSRN: https://ssrn.com/abstract=2263363 or http://dx.doi.org/10.2139/ssrn.2263363 [Accessed June 6, 2020].

17 Bekey, G. (2017) Autonomous Robots: From Biological Inspiration to Implementation and Control. MIT Press. p. 2

18 Russell, S. and Norvig, P. (1995) Artificial Intelligence: A Modern Approach. Third ed. Alan Apt. pp. 970-973

19 Gunkel, D. J (2018) Robot Rights. Massachusetts Institute of Technology. pp. 20-21 
to mechatronic devices. Robotics expands further and might also comprise remotely or human controlled devices, such as drones.

Moreover, to sum up the various views of what robots are, and what can they do or what can be done with them, I define two short but concise categories:

1. Hard-task robots: This category includes robots that explore the surface of Mars, dismantle bombs in the battlefields, perform manufacturing tasks in factories.

2. This category includes robots that are deployed in private spaces such as homes. These robots can carry our various tasks including, but not limited to, cleaning and cooking.

Finally, what is a "robot" for the purposes of this Article? It should be clear that such a definition excludes certain types of software-based AI systems that exerts no ability to manipulate the physical environments. In this Paper, I make use of the view of Ryan Calo, who emphasizes the "essential qualities" - embodiment, emergence, and social valence-that characterize robots as unique technologies. ${ }^{20}$

\subsection{SPECIFICITY OF HUMANOID ROBOTS}

Humanoid robots are the most sophisticated thinking machines among the robotic applications, not only in terms of the level of intelligence but also in aesthetics. They are becoming more integrated in our society. A large community of roboticists and AI researchers believe that human-like, also called anthropomorphic, humanoid, or android, machines are to become dominant and representative of AI. What they try to do is to develop human body-like organs, faces, noses, arms, legs, and speech capabilities that could move around in a human world and serve people in their homes. Examples of these machines are sex robots, tutor robots, or elderly carer robots. Those roboticist and AI researchers see an auspicious future for these robots and believe these robots will have important role to either complement humans or to help humans fulfill their desires and needs and amplify human capabilities. This point was noted by Ishiguro in an interview. He stated that "in Japan, we are moving from industrial

20 Calo, C (2012) Robots and Privacy. In Patrick Lin, Bekey G., Abney, K. (Eds.), Robot Ethics: The Ethical and Social Implications of Robotics (1st ed.) Cambridge, MA: MIT Press. 


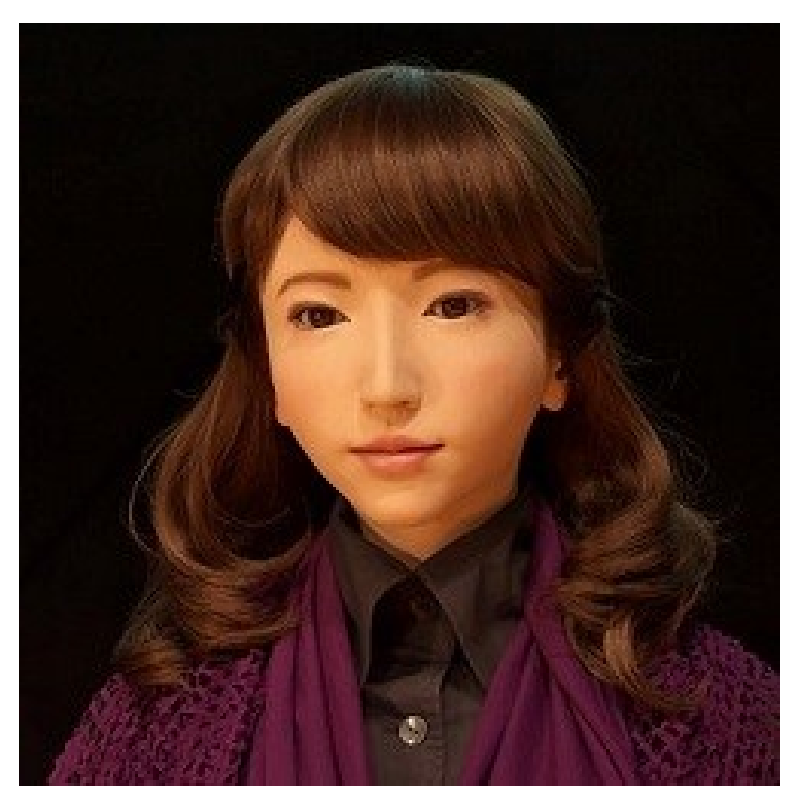

Figure 2. Photograph of Erica, Ishiguro's latest and most intelligent android.

robots - manufacturing robotics to HRics because for robots to be active in social contexts they should have a human-like appearance. When a robot has a human-like appearance, it can be easily recognized by humans because our brains recognize humans more naturally compared to other

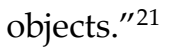

Along similar lines, in another interview, Gunkel, agreeing with Ishiguro, stated that "things happening in Japan seem to be at the leading edge of social robotics because of various cultural factors that have to do with the Japanese and the pressure of their social system with regard to declining birth rate and the need for caregivers in the home. Looking at Japan, we see that things might evolve elsewhere in the world because Japan is ahead of us here in Northern America and Europe." ${ }^{22}$ With their artificial body, they resemble the human one. ${ }^{23}$ The unique tasks HRs can get accomplished are manifold. They can be adaptable to new environments. With their shape and appearance, sophisticated human-robot interaction, they are believed, that they are humans.

21 Author's interview with Ishiguro (April 2021). The interview is available online at: Conversation with Nobel Minds https://www.youtube.com/channel/UChOFP5qUDU9Y6Y_u_bDZt4A.

22 Author's interview with Gunkel (May 2021). The interview is available online at: Conversation with Nobel Minds https://www.youtube.com/channel/UChOFP5qUDU9Y6Y_u_bDZt4A

23 Veruggio, O. G. (2008) Roboethics: Social and Ethical Implications of Robotics, in Springer Handbook of Robotics. 


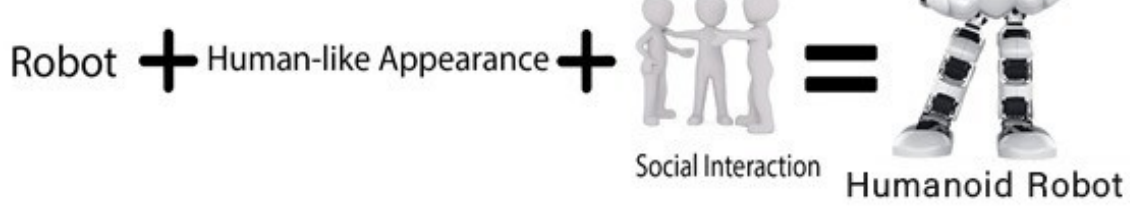

Figure 3. A humanoid robot

I make use of arguments and agree with scholars, such as Ryan Calo and Duffy, Fong et al., Breazeal, and Bartneck et al.,, who emphasizes the important of social interactivity, embodiment, emergence, and social valence - that characterize robots as unique technologies. ${ }^{24}$

Building on previous definitions, a HR, for the purpose of this Article, is:

"A virtual and physical entity supported with sensors, actuators, and mobility, human-like in appearance, and people might communicate with it in a natural social manner."

Considering this, a HR is a combination of three main components (see Figure 3). The three components make it get close to humaneness.

\subsection{ROBOT AND HUMANOID ROBOTS IN SOCIETY - NOW AND IN THE FUTURE}

Yet, before exploring futuristic views and scenarios, it is important and helpful to review some of today's statistics about robots and their use. In other words, answering the question: "Where are the robots in today's world?". As it became evident, robots, humanoid, industrial etc., are being used and deployed in a vast array of settings and for various purposes. The International Federation of Robotics (IFR) and The International Organization for Standardization (ISO), among other, provide useful updates about topical issues regarding robots and automation and their role in society. They annually report about the average robot density in both industrial and non-industrial environments. According to IFR's latest report about the density of robots in manufacturing industry, robots "hit a new global record of 113 units per 10,000 employees. By regions, Western Europe (225 units) and the Nordic European countries (204 units) have the most

24 Calo, (2012) Robots and Privacy. In Patrick Lin, George Bekey, Keith Abney (Eds.), Robot Ethics: The Ethical and Social Implications of Robotics (1st ed.) Cambridge, MA: MIT Press. 
automated production, followed by North America (153 units) and South East Asia (119 units)". ${ }^{25}$ In another IFR's report of 2020 shows "a record of 2.7 million industrial robots operating in factories around the world an increase of $12 \%$. Sales of new robots remain on a high level with 373,000 units shipped globally in 2019. This is $12 \%$ less compared to 2018, but still the 3rd highest sales volume ever recorded." ${ }^{26}$ Such figures might be interesting from the perspective of social robotics as industrial robotics is important, not only, for the progress of social robotics. Kanda and Ishiguro, notable roboticists, note that Japanese companies such as Sony and Honda developed key components of socially interactive robotics. ${ }^{27}$

As it is not possible to list all types of humanoid social robots, because they operate, or in the process of being developed to be deployed, in so many settings including, but not limited to, healthcare, education, entertainment, assistive living, domestic or household chores. These robots continue to experience a tremendous growth in the market and are deployed in to execute various tasks. Care robots and sex robots will be discussed briefly to give an overall imagine about the use of these HRs.

Care robots, as part one type of HRs that are deployed in nursing homes and hospitals or home healthcare robots, are currently at high level in health care sector and they are increasingly being integrated for different tasks. They can support human care, e.g., in cooking and cleaning for the elderly and the younger generation.

Sex robots are used for various purposes, but they are primarily socially interactive robots and created and used for sexual and intimate purposes, such as sexual stimulation. The provide two-ways of interaction, they are

25 The International Federation of Robotics. Available at: https://ifr.org/ifr-pressreleases/news/robot-race-the-worlds-top-10-automated-countries [Accessed Feb. 28, 2021].

26 The International Federation of Robotics. Available at: https://ifr.org/ifr-pressreleases/news/record-2.7-million-robots-work-in-factories-around-the-globe [Accessed Feb. 28, 2021].

27 Kanda, T., Ishiguro, H (2013) Human-Robot Interaction in Social Robotics. (1st ed.). CRC Press. Available at: https://doi.org/10.1201/b13004 [Accessed Oct. 10, 2020]. 


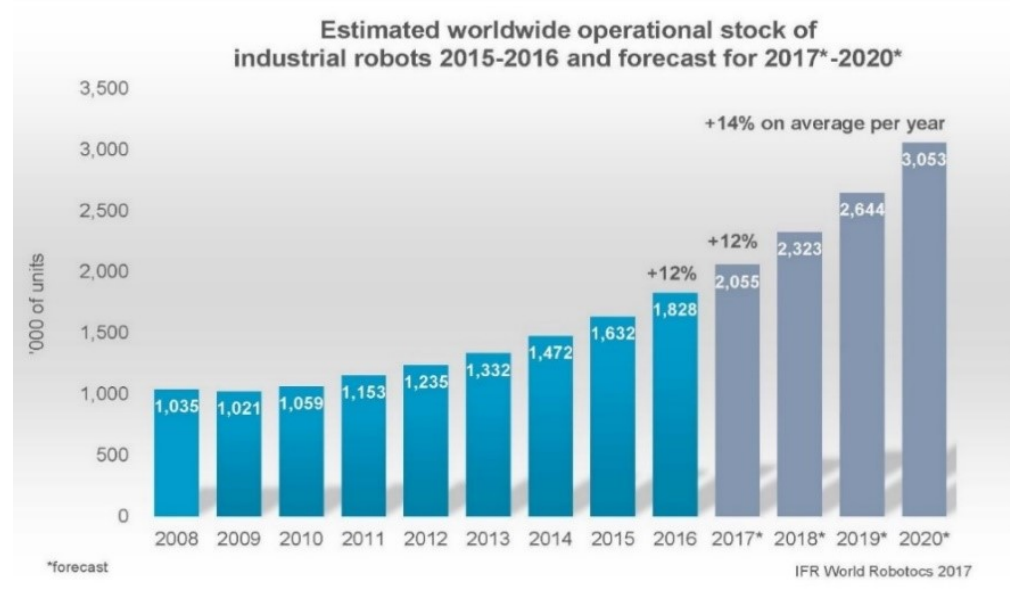

Figure 4.

equipped with cameras, speakers and microphones. For example, in addition to reasons related to lack of ability of some people (with physical disabilities, for example) to build intimate relationships with other humans, human-like features and development of AI techniques, presumably, sex HRs, as David Levy, one of the leading experts in AI argues, can be functionally autonomous, capable of learning, have physical support, and adapt to their environment. ${ }^{28}$

The market is not well established yet and so far, the history of social robotics indicates failures in promoting their products. One could claim that these robots suggest human-like capabilities, but this is more entertainment than practical utility beyond publicity. There have been several examples about this fact. Manufacturer Honda's iconic and most advanced HR of its time Asimo is one of them. The production of Asimo was halted in 2018. ${ }^{29}$ One the other side, we see some promising projects such as David Hanson's most celebrated HR Sophia. Sophia is an even more extreme case of publicity seeking with little commercial possibility. Sophia, according to the website wants to "connect with humans". ${ }^{30}$ Marketing this robot has been flourishing recently, particularly during the Pandemic. ${ }^{31}$ Sophia was

28 Levy, D. (2007). Love and Sex with Robots: The Evolution of Human-Robot Relationships. New York: Harper \& Co.

29 Honda (2019). Asimo: The world's most advanced humanoid robot. Available at: https://asimo.honda.com/ [Accessed April 2, 2020].

30 Hanson Dynamics. Sophia, Hanson Robotics' most advanced human-like robot. Available at: https://www.hansonrobotics.com/sophia/ [Accessed April 20, 2020]

31 Reuters (2020). Makers of Sophia the robot plan mass rollout amid pandemic. robot. Available at: https://www.reuters.com/article/us-hongkong-robot-idUSKBN29U03X [Accessed April 2, 2020]. 
granted honorary citizenship by the Kingdom of Saudi Arabia in 2017 marking a historical move. It was only in a Sci-Fi movie "Short Circuit (1986 film)", in which a non-human became a US citizen.

There are few other institutions are currently working on creating HRs such as Ishiguro's Laboratories and they generated a lot of attention. Genimoids, Erica, Telenoid, Elfoid, Hugvie, Android I are few examples. ${ }^{32}$ In an interview, Ishiguro claimed that "I want to bring robots to life". Their marketing seems to be very successful so far. Erica for example will be the first robot lead actress in a Hollywood movie. ${ }^{33}$ The Japanese information technology and investor giant, Softbank, has also a promising project, e.g., HRs Pepper. It's website states that Pepper is "the world's first social HR able to recognize faces and basic human emotions [...] Pepper is available today for businesses and schools. Over 2,000 companies around the world have adopted Pepper as an assistant to welcome, inform and guide visitors in an innovative way." 34 Softbank robotics has also another ongoing and promising project. Its robot NAO which "is also used as an assistant by companies and healthcare centers to welcome, inform and entertain visitors." NAO (and also Pepper) are used in various fields ranging from retail to tourism, health and education and there have been 5, 000 pieces sold around the world. ${ }^{35}$

All in all, we should, of course, exercise caution when studying how and in what speed technological developments are headed to. At this moment we can only say these developments are unpredictable and might likely fail not only in Japan but in other countries as well. This has been noticed by so many leading scholars. Among them, Melanie Mitchell who stated in her book Artificial Intelligence: A Guide for Thinking Humans (2019), that "We humans tend to overestimate AI advances and underestimate the complexity of our own intelligence."36 Moreover, an overview on the current advancements in AI indicates that the market of HRs

32 Hiroshi Ishiguro Laboratories. Robots. Available at: http://www.geminoid.jp/en/robots.html [Accessed April 2, 2020].

33 Hollywood just cast a robot actress in a $\$ 70$ million movie "Erica" will be the first robot lead actress. Available at: https://futurism.com/the-byte/hollywood-cast-robot-actress-movie [Accessed April 2, 2020].

34 Softbank robotics. Pepper. Available at: https://www.softbankrobotics.com/emea/en/pepper. [Accessed April 1, 2020].

35 Softbank robotics. Available at: https://www.softbankrobotics.com/emea/en/company. [Accessed April 1, 2020].

36 Mitchell, M. (2019). "Artificial Intelligence," “The Accusation," "Frankissstein," and "Red at the Bone." Available at: https://www.newyorker.com/magazine/2019/11/04/artificialintelligence-the-accusation-frankissstein-and-red-at-the-bone [Accessed April 1, 2020]. 
in particular is expected to flourish in terms of qualitative importance and quantitative and social impact on individuals interacting with them. Not only the market, academic institutions has been occupied following up with these advancements. Recently in the beginning of 2021, Oxford launched its "Institute for Ethics in AI," which aims to "bring together world-leading philosophers and other experts in the humanities with the technical developers and users of AI in academia, business and government." 37 Stanford did similar already in 2019 by launching "The Stanford Institute for Human-Centered Artificial Intelligence (HAI)", whose goals is "The mission of HAI is to advance AI research, education, policy and practice to improve the human condition." 38

A brief recap

It is clear that as technologies are fast evolving, the distinction between AI and robotics blur constantly. Perhaps having no absolute definition of "robot", when the AI-human-socio-cyber-physical-etc. mix is becoming so entangled and complex. Thus, AI embodied in robots, the meaning of robots might be shifted.

\section{THE GENESIS AND FUTURE OF PRIVACY \& THE ROLE OF HUMANOID ROBOTS}

Here is a recent scenario of our fictional story:

This is Pandora. She is a perfect and most sophisticated HR. And this is Kyllo, her owner. The relationship between the two becomes also deeper and more complex, and over time Kyllo expects Pandora to know what is right and what is wrong and what is private and what is not.

Is this a veridical, an illusory or a hallucinatory experience and, accordingly, relationship? Does such a relationship enshrine privacy-sensitive sides, and if yes, which ones specifically? This is an extreme and rather a fantasized example of relationship between humans and machines. However, this scenario does not mean that it is divorced from reality.

In this part, I distinguish between relevant concepts of privacy and the legal right to privacy. The aim is to create a Two-Pillar Structure and analyze different clusters of privacy, already identified in the literature and on which this Article intends to build. Part of the Article's original

\footnotetext{
$\begin{array}{llllll}37 & \text { Institute for } & \text { Ethics } & \text { in AI. [Accessed }\end{array}$ https://www.schwarzmancentre.ox.ac.uk/ethicsinai.

38 The Stanford Institute for Human-Centered Artificial Intelligence (HAI). Available at: https://hai.stanford.edu/about [Accessed August 10, 2020].
} 
contribution lies in the Two-Pillar Structure. HRs have alarming privacy implications on the virtual and physical environments; thus, the Two-Pillar Structure examines physical and non-physical (informational) privacy. For each cluster, I will briefly but concisely indicate the main relevant legal provisions on privacy at the international level. I will mention where and in what context these clusters overlap. Although these clusters of privacy may have some overlaps and are intrinsically intertwined and often coincide, they will be looked at and analyzed individually. This is an important approach to understand the effects which HRs generate in relation to privacy. The Two-Pillar Structure discussion will be complemented by a rather short, Two-Pillar Structure Plus section. This section examines further human rights implications generated by HRs but still associated with the right to privacy.

To provide further analysis, I introduce, in the following part, how privacy, as a philosophical and legal concept, has been conceptualized. While I consider the various philosophical and legal definitions of privacy within my initial discussions and which I find them constructive, I am not concerned with these definitions per se. Rather, what is important is what specific elements of privacy are impacted by HRs and in what context(s). In any event, although the term is conceptualized mostly by, or, at least, in conversations with, prominent philosophers on the field of privacy, such as John Locke and Immanuel Kant, my approach is human rights-focused particularly upon the information as a substantial and constitutive element of the right to private life. I trace the concept of privacy by adopting a nonreductionist account of the concept. That means that privacy is valuable in itself, and its value and importance are not derived from other considerations. ${ }^{39}$ The benefits of this approach are two-fold; (a) privacy is not conflated with data-protection, but the former's understanding paves the way for conceptualizing the latter, and (b) privacy helps to form a privacy-sensitive framework for a responsible and human-rights based development of HRs.

\subsection{PRIVACY AS A CONTROVERSIAL LEGAL AND PHILOSOPHICAL CONCEPT}

In this section, the idea is to find a philosophical answer to the question 'What is Privacy?'. I imagine that this step is crucial if one wants to build

39 See for example Rössler, B (2004) The Value of Privacy. Polity; 1st ed. 
a point of departure for questioning a legal definition of privacy and to investigate how courts and legislature employ the concept to identify intrusions upon the right to privacy. Next, it considers some debates within the discussions of privacy. This is important because, although, the term "privacy" is universally known, it is often seen as a disarray and unstable concept. It does not have a universal definition. ${ }^{40}$ Having said that, the upcoming conversations provide sophisticated insights into understanding what constitutes privacy. They also lead us to connect yesterday's with today's image of privacy. Both the former and the latter are based dominantly on a Western liberal ideology.

From the point of view of social and other sphere domains of life, privacy is a curious value. Younger and older generations in general, even in the current era of digital information, are still careful about who access to their private personal information. ${ }^{41}$ This is particularly true in the information society in which information, as many argue, inter alia, Floridi (2011) (cited in Richardson 2016, 146), is related to "who we are", as autonomous persons. ${ }^{42}$ What is interesting in the dominant discussions on privacy is that, although we are mindful of what is and is not private for us (think of the public debates following Edward Snowden's revelations), ${ }^{43}$ privacy is still a studied topic in the literature. This is surprising, since privacy (or secrecy) is an extremely well-investigated field in legal scholarship. Although it is frequently invoked in political and legal, discussions, and more than anything else in relation to our life in the digital age, the concept of privacy is in its core philosophical. The concept tells us about human nature and human needs to engage in activities that are exercised in a private sphere. Perhaps, the earliest text that directly discusses the distinction between the personal and public spheres is the first book of Aristotle's Politics. In addition to outlining the distinction in clear

$\overline{40}$ See various opinions on the definition of privacv in, for example, Nissenbaum, H. (2010) Privacy In Context: Technology, Policy, And The Integrity Of Social Life. Stanford University Press.

41 Van den Hoven, J, Blaauw, M. Wolter, P. and Warnier, M (2020). Privacy and Information Technology, The Stanford Encyclopedia of Philosophy, Edward N. Zalta (ed.), https://plato.stanford.edu/archives/sum2020/entries/it-privacy.

42 Richardson, J. (2016) Law and the Philosophy of Privacy. Routledge. (1 ${ }^{\text {st }}$ edit) p. 146. See also Balkin, Jack M., Information Power: The Information Society from an Antihumanist Perspective (2006). Available at SSRN: https://ssrn.com/abstract=1648624 or http://dx.doi.org/10.2139/ssrn.1648624.

43 See some key discussions on privacy, following Snowden's revelation Lyon, D. (2013) Surveillance, Snowden and Big Data. Big Data \& Society. Rotenberg, M (2015). Privacy in the Modern Age: The Search for Solutions. Scott, J. (Edit), Horwitz, J. (Editor). The New Press. 
terms, it is still helpful by providing a sophisticated understanding of "privacy" and a useful starting point, since it has consistently performed as a point of reference for later debates on privacy. Aristotle makes a distinction between the oikos - private family life or best translated as household - as a distinct sphere of life, and the polis - the public realm of the political community. The former is, for Aristotle, the basic unit of the latter and, in addition, its existence is necessarily determined by the latter. Aristotle states that:

"......Thus also the city-state is prior in nature to the household and to each of us individually......It is clear therefore that the state is also prior by nature to the individual; for if each individual when separate is not self-sufficient, he must be related to the whole state as other parts are to their whole, while a man who is incapable of entering into partnership, or who is so self-sufficing that he has no need to do so, is no part of a state, so that he must be either a lower animal or a god." 44

In various academic arenas, privacy is believed to be a very complex and contextual concept. Which means in certain contexts people might be concerned about their privacy but in others they might not. It is also believed that privacy is of the concepts that have not, and perhaps will never capture a universal recognition in terms of definition or understanding. This is also linked to the speed of technological development with affects various social, economic, and legal domains in our society. The rapid evolution of Information and Communication Technologies (hereinafter ICT), AI, robotics, and other technologies make it difficult to anticipate with certainty their impacts on our societies, including the social and legal interests of individuals. Consequently, it is also difficult to specify precisely and non-controversially the contours of the very concept of privacy. The absence of a definition or common understanding does and should not, however, refrain us from offering a reasonably solid conceptualization of privacy for the purposes of a legally binding understanding of the concept.

44 Aristotle (1944) in 23 Volumes, Vol. 21, translated by H. Rackham. Cambridge, MA, Harvard University Press; London, William Heinemann Ltd. 1944. 1.1253a. 
In the age of the digital world and rapid technological transformation, privacy, both as a value and a human right, has moved to the center of attention of academic scholarship that focuses on legal and social science. Many academic works on privacy have so far followed the "traditional method". ${ }^{45}$ By applying this method, they tried to articulate the features that separate privacy from other values. They tried to see what is unique about privacy and next how to characterize it. Some of them looked "for sets of necessary and sufficient elements that single out privacy as unique with regard to other concepts". ${ }^{46}$ However, this approach is arguably not the most successful. Perhaps because privacy encompasses a vast range of values and principles, e.g., freedom of thought, right to personality, control of information, solitude in one's home and private spaces. ${ }^{47}$

Several philosophers, political scientists, and legal theorists have attempted to define the concept of privacy. Solove (2004) observes that they have notoriously failed in reaching a satisfying common ground. ${ }^{48}$ Also, Gutwirth (2002) notes that privacy is under-investigated and it "remains out of the grasp of every academic chasing it." He continues stating that privacy "still finds a way to remain elusive."49 In a similar manner, Cohen (2013), claims that "privacy has an image problem" ... and that "the recent additions of social media, mobile platforms, cloud computing, and AI-driven data mining now threaten to tip the scales entirely, placing privacy in permanent opposition to the progress of knowledge." 50 Furthermore, Helen Nissenbaum is of the idea that argues privacy, as a human value, is identified and understood through "contextual integrity". Nissenbaum refers to the idea that sharing of information that is not the problem per se. For her, the problem is by sharing of information outside of "socially agreed contextual boundaries." In this sense, people who complain about "the violation of their privacy generally understand that sharing

$\overline{45}$ See for example Cannataci, J. A. (2016) The Individual and Privacy, Routledge, V.1

46 See generally, Solove, D. J (2002). Conceptualizing privacy. Calif. L. Rev.

47 Article 8 - Right to respect for private and family life, home and correspondence of the ECHR jurisprudence covers various aspects of privacy. See Council of Europe's Guide on Article 8 of the European Convention on Human Rights (31 August 2020). https://www.echr.coe.int/documents/guide_art_8_eng.pdf.

48 Solove, D. J. (2004) The Digital Person Technology and Privacy in the Information Age. NYU press. P. 2.

49 Gutwirth, S (2002) Privacy and the information age. Lanham, MD: Rowman \& Littlefield. p 30

50 Cohen, J. E. (2013) What Privacy is for, 126 HARV. L. REV. 1904, 1907 
of information is crucial to social life and that their real concern is the inappropriate and improper sharing of information". ${ }^{51}$

Some scholars have developed "essentialist" or "unitary" theories of privacy. ${ }^{52}$ They attempted to identify the core of privacy and how privacy, as a single concept, is different from other concepts. While on the other hand, others have adopted a "reductionist" approach. ${ }^{53}$ With this approach, they attempted to use privacy as an instrument to discover other human rights and values such as human liberty and autonomy.

Other scholars refuted the way that privacy is defined through a "conceptual core". ${ }^{4}$ They hold that privacy can be identified by "developing pluralistic accounts of privacy interests or forms of intrusion to identify "cluster[s] of problems" that share family resemblances. ${ }^{55}$

Privacy and Technology

Various academic literature holds that the concept of privacy is about responding to the developments that come along, essentially, ICT, and other types of technologies. Looking at the intersection between privacy and technology, scholars started already in 1890s to look at the impacts of technology on privacy. The emergence of portable photography and its use in our society kicked out the discussions on this relationship. Historical legal texts trace the expression "right to privacy" to Samuel Warren and Louis Brandeis. ${ }^{56}$ Warren and Brandeis summarized privacy as the right of the individual to "be let alone" and expanded the notion of data protection beyond the fundamental right to privacy. "The right to be let alone" late became the most definition referred to when discussing privacy and the right to privacy in legal texts. It could be argued also that there is no single legal text on privacy that does not mention Warren and Brandeis's summary of the right to privacy.

Back time when Warren and Brandeis wrote their opinions on privacy, the technology of photography was used to collect data and information about individuals without their consent, and they phrased privacy not as a philosophical concept only but also, legally as the "right to be let alone"57

51 Nissenbaum, H (2004) Privacy as Contextual Integrity, Washington Law Review, 79:1, 101-139.

52 Solove, D. J. (2002) Perspectives in privacy in information privacy law. 90 Cal. L. REV. 1087. p. 44.

53 Solove (2014), 4, at 14.

54 Thomson, J. J. (1975) The Right to Privacy, 4 PHIL. E PUB. AFF. 295, 312-13.

55 Cohen, 3, at 1907-08.

56 Warren, S. and Brandeis, L. D. (1890) The Right to Privacy, Harvard Law Review.

57 Ibid, 43, at 193. 
which courts should understand privacy as an individual's freedom to solitude. This in turn inspired significant interest in and attention to privacy not only in the US legal system but internationally as well.

Additionally, in a famous technology-privacy-related case, Olmstead v. United States (1928), Brandeis called for establishing and safeguarding a right to privacy, describing such a right as "the most comprehensive of rights and the right most valued by civilized men."58 In addition to his Article, several scholars argue that Brandeis's dissent in Olmstead undoubtedly was fundamental in the making of the law of privacy, both domestically and internationally, as hailed by a multitude of scholars and on subsequent theories of privacy. However, we might be misled if we insist that the formulation of privacy as a "right to be let alone" is sufficient. Martin Scheinin offers an opinion on it, noting that the phrase merely describes an attribute of privacy. For him, an understanding of privacy as merely "being let alone" fails to provide a comprehensive understanding of what privacy really is. For him, the right to privacy is largely about "making a choice". Scheinin asserts that the right to privacy is about "the ability to preserve the private sphere" and that "it depends heavily on the attributes of individual's social environment." He would claim that privacy involves one's relationship to society; in a world without others, claiming that one needs privacy would not make much sense. ${ }^{59}$

I tend to favor the idea that even when we are exercising our right to privacy, we are somehow and in one way or another connected to the outer world. We are influenced by others and our privacy is defined by our social relationships. To put it in Aristotelian words, we are, as social animals, caught in a natural web of necessity.

In a similar way to Scheinin's interpretation of privacy, William Prosser noted, in his famous California Law Review article 'Privacy', that Warren and Brandeis saw privacy as "public disclosure of embarrassing private facts about the plaintiff." ${ }^{60} \mathrm{He}$ disapproved and criticized this narrow vision of privacy rights and claimed that these rights must go beyond physical intrusion. In his own words, he divided privacy rights into four categories: "Intrusion upon a person's seclusion or solitude, or into his private affairs;

58 Olmstead v. United States, 277 U.S. 438, 478 (1928) (Brandeis, J., dissenting).

59 Ibid, Scheinin. Scheinin, M. (2009) Report of the Special Rapporteur on the promotion and protection of human rights and fundamental freedoms while countering terrorism, $\mathrm{A} / \mathrm{HRC} / 13 / 37$.

60 Prosser, L. W., (1960) Privacy, California Law Review 48 383, 388-89. 
Publicity placing one in a false light in the public eye; and Appropriation of one's likeness for the advantage of another."

Finally, one can claim that Louis Brandeis and Alan Westin provided the most important understanding of privacy. This understanding influenced the way various jurisdictions in various countries see privacy. Many claims also that every country adopted their understanding of privacy. Moreover, Westin's 1967 classic Privacy and Freedom enriched very significantly the philosophical and legal groundwork for the academic discussions on the intersection between technology and privacy as well as personal freedom as an integral element of privacy and is considered a foundational text in the field of privacy law. ${ }^{61}$ The US Supreme Court went along with Westin's views stating that "understanding privacy encompass the individual's control of information concerning his or her person" in one of it is famous judgments. ${ }^{62}$

\subsection{TYPOLOGY OF PRIVACY: THE TWO-PILLAR STRUCTURE AND TWO-PILLAR STRUCTURE PLUS}

In this sub-section, my aim is to discuss important academic literature on privacy. Whereas it is not possible (and also not of present interest, considering this Article's limited scope) to discuss many of the privacyrelated existing classificatory academic works. Believing that this will assist in making sense of how such classifications can become relevant to the topic at hand.

\subsubsection{CLUSTER ONE: NON-PHYSICAL (INFORMATION) PRIVACY}

\subsubsection{SUB-TYPE: INFORMATION PRIVACY}

The informational dimension of privacy is strongly and most directly affected by humanoid robots (HRs). There are some academic claims which states that it is all about information and how our information is impacted.

Natural human-machine (robots called machines also) interaction is an emerging field on a large scale, particularly regarding HRs. These robots can execute various tasks, from controlling other smart devices at home to reporting about the weather, news, appointments, supporting music streaming and sending notifications to family members in case of an emergency. To provide this vast array of functionalities, robots, be it HS or other types, are empowered with different technological equipment

61 Westin, A. F (1968) Privacy and Freedom, 25 Wash. \& Lee L. Rev. 166.

62 DOJ v. Reporters Comm. for Free Press, 489 U.S. 749 (1989). 
such as sensors and cameras. These robots use supporting cloud services and connected social media platforms. As a result, these robots inevitably effect and relate to privacy. ${ }^{63}$ Similar to mobile phones or computers, HS are connected with the clouds to which the transfer data of the environments they are serving, or they are installed at. These set of data is about general and private information that are related to the environments and the individuals interacting with them. From the type of music and movies to the type of product purchase these individuals prefer.

Consequently, the relevance of HRs to the discussion of information privacy is clear. In light of the revelations regarding mass surveillance, interception and data collection, the General Assembly of the United Nations recognized the human rights relevance to digital privacy by adopting the Resolution 68/167 titled "The right to privacy in the digital age". ${ }^{64}$ In that resolution, the General Assembly affirmed that "the rights held by people offline must also be protected online" and called upon all States to respect and protect the right to privacy in digital communication. The resolution reaffirmed the human right to privacy, according to which "no one shall be subjected to arbitrary or unlawful interference with his or her privacy, family, home or correspondence, and the right to the protection of the law against such interference." 65

For the purpose of this Article, I consider that the right to privacy in the Declaration and the General Assembly Resolution has an informational aspect.

\subsubsection{SUB-TYPE: PRIVACY OF COMMUNICATION}

Humanoid robots (HRs), empowered by Cyber-Physical systems (CPSs), are able to impact not only the virtual but also the physical sphere. Consequently, HRs can create a disquieting impact on the privacy of communication. No wonder that the right to privacy encompasses privacy of communication which refers to individuals' anonymity and confidentiality. It is not necessarily HRs violate this right, they could empower it.

63 For further discussion of the human rights implications presented by AI and robotics, see Ford, M (2015) Rise of the robots: Technology and the threat of a jobless future. Basic Books, New York.

64 The right to privacy in the digital age - Report of the Office of the United Nations High Commissioner for Human Rights. Resolution 68/167. (2018).

65 Ibid. The right to privacy in the digital age - Report of the Office of the United Nations High Commissioner for Human Rights. Resolution 68/167. (2018). 
Individuals who create intimate relationships with their HRs (sex robots are the most obvious example) and share sensitive information with them, put themselves in a particularly vulnerable situation vis-à-vis the HRs (by being hacked or damaged remotely, for example). It might be argued that the states have a higher responsibility to protect individuals because of the particular vulnerability that is involved. This type of privacy can be claimed under Article 8 of the UDHR.

\subsubsection{SUB-TYPE: PRIVACY OF BEHAVIOR AND ACTION}

The right to privacy is strongly encompassed different dimensions of privacy. For example, it is related to individuals' ability to resist "behavioral manipulation", "protection of sensitive information", "protection of personal matters such as religious and sexual practices", "autonomy and self-determination", to name a few. Being independent from others (individuals, state apparatus, tech companies...etc.) contributes to "the development and exercise of autonomy and freedom in thought and action". 66

HRs, through their use for anticipating and guiding behavior and action enabled by detection of emotions (affective computing), and for assessing individuals, may negatively affect an individuals' right to make independent decisions. Clarke (1979) notes that "there is a special element included in the privacy of personal behavior, whereby people have a right to private space to carry out particular activities." ${ }^{67}$ In this regard, DeCew notes that privacy "is not merely limited to control over information. Our ability to control both information and access to us allows us to control our relationships with others. Hence privacy is also connected to our behavior and activities."68 Although not referring specifically to robots or HRs, Lawrence Lessig argues that "combinations of computer hardware and software could constrain and direct human behavior". ${ }^{69}$

For our purpose, I consider that the right to privacy includes a set of human behavior that are essential part of private life protected. Of course, this set of human behavior requires protection from any violation.

66 Nissenbaum, H (2010) Privacy in Context: Technology, Policy and the Integrity of Social Life. Stanford CA: Stanford University Press.

67 Clarke, R (1979). Introduction to Dataveillance and Information Privacy, and Definitions of Terms. http://www.rogerclarke.com/DV/Intro.html.

68 Wagner, J. D. (2015) The Feminist Critique of Privacy: Past Arguments and New Social Understandings, in Social Dimensions of Privacy: Interdisciplinary Perspectives. (Beate Roessler \& Dorota Mokrosinska eds. 3.4.

69 Lessig, L (1999) Code: And Other Laws of Cyberspace .1st ed. pp. 88-89. 


\subsubsection{SUB-TYPE: PRIVACY OF THOUGHTS AND FEELINGS}

Humanoid robots (HRs) influence individuals' privacy of thoughts and feelings. This is true because HRs are engaged in digital and physical manifestations. Concerning this specific discussion, Finn et al., in their typology of privacy (2013) note that "the privacy of thoughts and feelings can be distinguished from the privacy of the person, in the same way that the mind can be distinguished from the body." 70

HRs, supported by latest technological techniques such as algorithms, are declared, as several studied mentioned previously suggest, to be more humanistic. In other words, they are similar to humans in terms of appearance and actions. This has been declared also by one of the leading scholars in human robotics such as Hiroshi Ishiguro. ${ }^{71}$

The way HRs look and behave may eventually make it possible (or at least easier in comparison to other non-human like technologies) to access individuals' thoughts and feelings. ${ }^{72}$ In the view of Finn et al., privacy of thoughts and feelings "protects what is perhaps the least controversial, most consistent and unwavering dimension of privacy, the individual thoughts and feelings which until now were almost entirely imperceptible to others unless individuals chose to share them". ${ }^{73}$

\subsubsection{CLUSTER TWO: PHYSICAL PRIVACY}

\subsubsection{SUB-TYPE: PHYSICAL PRIVACY}

Another dimension of privacy worth mentioning is physical privacy. Regarding this one, the physical embodiment of HRs is what makes them a unique type of technology compared to, for example, merely virtual technologies such as Chatbots. Because of the cumulative effect of their hardware, operating system, and software, they can interact with their environment and have physical impacts on physical spaces. In addition to this, Calo notes that, "their programmability and interactivity and their ability to physically reach out into the world in an autonomous fashion enable

70 Finn, R. L., Wright, D. and Friedewald, M. (2013). "Seven types of privacy", in Gutwirth, S. Leenes, R., De Hert, P. and Poullet, Y. (eds.), European Data Protection: Coming of Age, Springer, Dordrecht, $\mathrm{p} 4$.

71 Author's interview with Ishiguro (Feb 8, 2021). The interview is available online at the YouTube channel: "Conversation with Nobel Minds" https://www.youtube.com/channel/UChOFP5qUDU9Y6Y u bDZt4A [Accessed on 18 May 2020].

72 Subramanian, R (2017) Emergent AI, Social Robots and the Law: Security, Privacy and Policy Issues. Journal of International Technology and Information Management ,Volume 26। Issue 3, 97

73 Ibid, Finn et al, 18. 
robots to survey individuals across places and gain access to personal rooms, which was impossible at this scale before" ${ }^{\prime 4}$

Scholars often make a clear distinction between physical and non-physical privacy and consider them as distinct forms of privacy. Here I support the conclusion of Blok and others who argue that "informational privacy should not be put alongside relational, spatial, and communicational privacy, but rather should be seen as the other side of the coin." All (more or less) "physical types of privacy lie on one side, and informational privacy on the other". ${ }^{75}$ I reiterate that in the case of HRs, equipped with technological sophistication, the distinction between these two kinds of privacy may be far less important to the privacy protection than it seemed before, because the boundaries between these two kinds will increasingly blur the more technological innovation advances.

\subsubsection{SUB-TYPE: PRIVACY OF LOCATION AND SPACE}

"Privacy of location and space" refers to the idea that individuals should be free in physical spaces with the freedom of navigating without being watched or monitored. This type of privacy is known also as "Spatial privacy". Spatial privacy may be easily perceived as one of the cornerstones of privacy protection, since it points directly to individuals' right to solitude and a right to privacy in spaces. ${ }^{76}$ Home is here a most characteristic notion associated with this type of privacy. For example, the ECtHR, in Niemietz $v$ Germany, considered "business premises" as a space that sometimes also falls under the notion of "home", if what happens there is linked to someone's private life. ${ }^{77}$ Many of the international treaties, e.g., UDHR, considered in this article protect the home, but one might also argue that they protect all other places, e.g. a car or an office, to name a few. ${ }^{78}$ These physical places are where individuals enjoyed their privacy.

In addition to the ability to move around rooms, kitchens and other small private spaces, HRs may come with programming that enhances their capacity for stealth movement. ${ }^{79}$ A potential privacy intrusion here may involve a HR invading the privacy of a person's intimate life. This can occur,

$\overline{74}$ Calo, M, R (2014) Robots and Privacy," in Robot Ethics: The Ethical and Social Implications of Robotics (Patrick Lin, George Bekey, and Keith Abney, eds.) 4.

75 Bok, S. (1983) Secrets: On the Ethics of Concealment and Revelation 10-11. Oxford University Press, cited in Koops, B. K, Newell, B. N., Timan, T. Škorvánek, I. Chokrevsk, T. Masa G. (2017) A Typology of Privacy.

76 Clarke ibid.

77 See ECtHR 16 December 1992, Niemietz v Germany, App. 13710/88.

78 ECHR (art. 8), art. 12 of the UDHR. See also EU (art. 7). For general discussion on this issue, see Wright, F \& Friedewald, 4. 
for example, when a HR with cameras, looks through a bedroom window and taking photographs or recording voices. This scenario can happen where a HR is either acting autonomously or being remotely controlled. There are clear indications of potential overlaps with other aspects of privacy, for example with the informational privacy of people in places being scanned.

This type of privacy links strongly to social privacy (to be discussed right below). The concept of physical space is seen part of a community or a family. Westin states that this type of private space (or, in his own term, "intimate zone") is not limited to one person or two persons or to an intimate relationship. In his understanding, the concept refers to the intimate relationship of an individual with his or her family, friends or neighbors. ${ }^{80}$

\subsubsection{SUB-TYPE: SOCIAL PRIVACY}

The integration of humanoid robots (HRs) in the private spheres might affect the person's right to social life/social privacy. Social privacy is also termed "private social life" or "privacy of association" in different legal texts. In this regard, Article 8 of the ECHR - Right to respect for private and family life, home and correspondence - protects the right to identity and personal development, which includes the right to establish and develop relationships with other human beings and the outside world. This fact has been relevant in Munjaz v. United Kingdom, in which the ECtHR stated that the right to privacy also protects "the right to establish and develop relationships with other human beings and the outside world." ${ }^{81}$ In another important decision, the ECtHR stated that, "[r]espect for private life must also comprise to a certain degree the right to establish and develop relationships with other human beings. ${ }^{82}$

\subsection{TWO-PILLAR STRUCTURE PLUS}

Along the Two-Pillar Structure of Physical and Non-Physical (information) Privacy discussed so far, one can position other relevant objectives that attached to privacy in the context of HRs. My aim is to demonstrate that

\footnotetext{
79 Calo, R (2014) Robots and Privacy," in Robot Ethics: The Ethical and Social Implications of Robotics (Patrick Lin, Bekey, G and Keith Abney, eds.) 4.

80 Westin, A, F (1968) Privacy and Freedom. 25 Wash. E Lee L. Rev. 166, https://scholarlycommons.law.wlu.edu/wlulr/vol25/iss1/20.

81 Munjaz v. United Kingdom, 30 Eur. Ct. H.R. (2012)

82 Niemietz v. Germany, 10 Eur. Ct. H.R. (1992).
} 
an enhanced Two-Pillar Structure Plus enables observing further implications to human rights as generated by HRs. ${ }^{83}$

The right to reputation is an important privacy aspect that is potentially undermined by HRs. Cloud computing enables HRs to interact with their surroundings and interact with individuals in private spaces. By facilitating the distribution of data, HRs can facilitate the spread of information which consequently generates impacts, positive or negative, $\mathrm{o}$ the reputation of individuals. Looking at human rights treaties, one can see the right to reputation being recognized as an important part of privacy and its protection.

Again, this should not be seen as an exclusive privacy-related list of rights and values that are relevant in the context of the deployment of HRs. Future work demands an extension of this section to consider, for instance, the right to personal autonomy, the right to the security of the person, the right to personality and so forth.

\section{CONCLUDING REMARKS}

Privacy is more than one single idea, it is multifaced concept. The Article attempted to demonstrate that privacy as a multidimensional concept that matters to older and younger generations. The Article also suggested that this multidimensionality is useful to evaluate the impacts of HRs on individuals. The case study discussion above demonstrated the potential impact of HRs potentially upon different types of privacy. The Article argued that it might, at some point in the future, challenge the very traditional physical and non-physical dimensions of privacy and the current list of clusters must always be ready to expand as, it seems, new technologies, e.g., HRs, emerge and will constantly challenge privacy.

To analyze these distinctive privacy challenges generated by HRs, the Article provided various theoretical perspectives relevant to privacy and human-machine interaction. It is worth noting, however, that as innovation in robotics proceeds, the categorization of the various dimensions of privacy

83 In a relevant matter, the European Commission's Ethics Guidelines for Trustworthy AI, for instance, accord "a foundational role to human rights law in the age of AI. The Guidelines support an approach to AI ethics based on the fundamental rights enshrined in the EU Treaties, the EU Charter and international human rights law. Respect for fundamental rights, within a framework of democracy and the rule of law, provides the most promising foundation for identifying abstract ethical principles and values, which can be operationalized in the context of AI." European Commission 2019, 9. 
presented does not necessarily provide the only comprehensive and adequate framework of privacy.

Lastly, the Article contended that new and emerging technologies, particularly HRs with their cumulative effect of hardware (human-like appearance) and software, have introduced novel privacy threats. I also think that the Two-Pillar Structure and Two-Pillar Structure Plus are sufficiently flexible to accommodate potential new developments that are likely to take place in the rapidly evolving field of technology.

\section{ACKNOWLEDGEMENT}

This paper is a contribution to the Cyberspace conference in Brno, Czech Republic and it is a part of my doctoral research project I pursue at the European University Institute in Florence, Italy. I would like to thank individuals working for the Masaryk University Journal of Law and Technology, including the editor Jakub Harašta for giving me the opportunity to present my doctoral research at the conference and for publishing this paper.

Many wonderful people have been so generous to contribute to this paper and to my doctoral research project in general. I have benefited a lot from valuable reflections made by Prof. Giovanni Sartor (EUI/Uni. Of Bologna), Prof. Marc Rotenberg (Georgetown Uni./CAIDP), Prof. Ben Shneiderman (Uni. Of Maryland) Prof. David Gunkel (Northern Illinois Uni.) Prof. Sofia Ranchordas (Uni. Groningen), Dr. Bethany Shiner (Uni. Of Oxford/Middlesex), judge George Aeon, Dr. Mikko Häkkinen (Laurea), and Isabele Rodrigues (UFPE).

\section{LIST OF REFERENCES}

[1] Allen, L, A (2011) Unpopular Privacy: What Must We Hide? New York: Oxford University Press.

[2] Aristotle (1944) in 23 Volumes, Vol. 21, translated by H. Rackham. Cambridge, MA, Harvard University Press; London, William Heinemann Ltd.

[3] Asimov, I (1950) Liar. In Astounding Science Fiction, Reprinted in "I, Robot".

[4] Balkin, J. M. (2016) Information Fiduciaries and the First Amendment. UC Davis Law Review. Vol. 49, No. 4.

[5] Bekey, G (2017) Autonomous Robots: From Biological Inspiration to Implementation and Control. Paperback. 
[6] Bryson, J. J (2009) Robots should be slaves. Artificial Models of Natural Intelligence University of Bath, BA2 7AY, United Kingdom.

[7] Calo, R (2012) Robots and Privacy. In Patrick Lin, George Bekey, Keith Abney (Eds.), Robot Ethics: The Ethical and Social Implications of Robotics (1st ed.) Cambridge, MA: MIT Press.

[8] Calo, R (2014) Robots and Privacy, in Robot Ethics: The Ethical and Social Implications of Robotics. Patrick Lin, Bekey, G and Keith Abney, eds.

[9] Calo, R (2015) Robotics and The Lessons Of Cyberlaw, 103 Calif. L. Rev. 1.

[10] Cannataci, J. A. (2016) The Individual and Privacy, Routledge, V.1.

[11] Cerka, P. et al, (2015) Liability For Damages Caused By AI, Computer Law \&Security Review.

[12] Cohen, J. E. (2013) What Privacy is for, 126 HARV. L. REV. 1904, 1907.

[13] Darling, K (2012). Extending legal protection to social robots: The effects of anthropomorphism, empathy and violent behavior towards robotic objects.

[14] Fong, T., Nourbakhsh, I., and Dautenhahn, K (2002) A survey of socially interactive robots. Robotics and autonomous systems, 42, no. 3-4.

[15] Fosch-Villaronga. E., Millar, C. (2018) Cloud Robotics Law and Regulations, Challenges in the Governance of Complex and Dynamic Cyber-Physical Ecosystems.

[16] Koops, B. K, Di Carlo, A. Nocco, L. Cassamassima, V. Elettra, S (2913) Robotic technologies and fundamental rights. International Journal of Technoethics.

[17] Gavison, R (1980) Privacy and the Limits of Law, 89 YALE L.J.

[18] Gunkel, D. J (2018) Robot Rights. Massachusetts Institute Of Technology.

[19] Gutwirth, S (2002) Privacy and the information age (Lanham, MD: Rowman \& Littlefield, 30.

[20] Lessig, L (1999) Code: And Other Laws of Cyberspace 1st ed.

[21] Minsky, M (1969) Semantic information processing. Cambridge, MA: MIT Press.

[22] Nissenbaum, H (2004) Privacy as Contextual Integrity, Washington Law Review, 79:1.

[23] Nissenbaum, H (2010) Privacy in Context: Technology, Policy and the Integrity of Social Life. Stanford CA: Stanford University Press.

[24] Richardson, J. Law and the Philosophy of Law. Routledge. 2016.

[25] Prosser, L. W., (1960) Privacy. California Law Review.

[26] Richards, N. M., Smart, W. D (2013) How Should the Law Think About Robots?

[27] Rössler, B (2004) The Value of Privacy. Polity; 1st ed. 
[28] Sartor, G. (2017). Human Rights and Information Technologies. The Oxford Handbook of Law, Regulation and Technology.

[29] Scheinin, M. (2009) Report of the Special Rapporteur on the promotion and protection of human rights and fundamental freedoms while countering terrorism, A/HRC/13/37.

[30] Snow, C. P (2993) The two cultures: and a second look. Cambridge Univ. Press, Cambridge.

[31] Stuart, R., and Norvig, P. (1995) Artificial Intelligence: A Modern Approach.

[32] Subramanian, R (2017) Emergent AI, Social Robots and the Law: Security, Privacy and Policy Issues. Journal of International Technology and Information Management.

[33] Syamimi, S., Yussof, H., Ismail, L. I., Mohamed, S., Hanapiah, F. A., and Zaharid, N. I (2012) Initial Response in HRI- a Case Study on Evaluation of Child with Autism Spectrum Disorders Interacting with a Humanoid Robot NAO. Procedia Engineering (IRIS).

[34] Szabolcsi, R (2014) The Birth of the Term Robot. AiMT Advances in Military Technology Vol. 9, No. 1.

[35] Turing, A. M. (1950) Computing Machinery and Intelligence, Mind, New Series, Vol. 59, No. 236.

[36] Wagner, J. DeCew (2015) The Feminist Critique of Privacy: Past Arguments and New Social Understandings, in Social Dimensions Of Privacy: Interdisciplinary Perspectives. (Beate Roessler \& Dorota Mokrosinska eds.).

[37] Warren, S. and Louis D. Brandeis, L. D. (1890) The Right to Privacy, Harvard Law Review 4.

[38] Westin, A. F (1968) Privacy And Freedom, 25 Wash. E Lee L. Rev.

[39] William, R (1999) The International Dictionary of AI. The Glenlake Publishing Company. 